\title{
ANALISIS KEBIJAKAN UNTUK PENGELOLAAN MINYAK DAN GAS (STUDY KASUS LAPANGAN “X”)
}

\author{
Ramli Nonci ${ }^{1}$, Akhmad Fauzi ${ }^{2}$, Fifi Diana Thamrin ${ }^{3}$ \\ ${ }^{1,2,3}$ Institut Pertanian Bogor, Indonesia \\ Email: ${ }^{1}$ nonci2003@gmail.com
}

\begin{abstract}
Indonesia is one of the countries in the world that have potential of natural resources such as oil and gas. As a resource, that plays an important role in the economic life, the use of oil and gas needs to be managed properly. One of the resources of oil and gas that have significant production value and impact to the economy of Indonesia is the " $X$ " field at East Kalimantan. This study aims to provide analyze policies that can encourage the management of the remaining oil and gas fields more optimally. Data used in the study came from the results of the discussions, field observations, literature review government policies and company documentation on 2019. The analytical tool used is the multi criteria decision analysis (MCDA) method. Based on the analysis of policies for the development of the " $X$ " field by taking into account economic, social, and HSE (Health, Safety and Environment) criteria results in a conclusion that Gross Split policy alternative has the highest value compared to the Cost Recovery policy and the Cost and Fee policy for the design of oil and gas management policies.
\end{abstract}

Keywords: reserves, policy, oil and gas, multi criteria decision analysis

\section{ABSTRAK}

Indonesia merupakan salah satu negara di dunia yang memiliki potensi sumber daya alam berupa minyak dan gas bumi. Sebagai sumber daya yang berperan penting dalam kehidupan perekonomian, pemanfaatan minyak dan gas bumi perlu dikelola secara baik dan benar. Salah satu sumber daya minyak dan gas bumi yang memiliki nilai dan dampak produksi signifikan bagi perekonomian Indonesia adalah lapangan " $X$ " di Kalimantan Timur. Penelitian ini bertujuan untuk menganalisis kebijakan yang dapat mendorong pengelolaan lapangan minyak dan gas yang tersisa lebih optimal. Data yang digunakan dalam penelitian bersumber dari hasil diskusi, observasi lapangan, studi literatur kebijakan pemerintah, dan dokumentasi perusahaan pada tahun 2019. Alat analisis yang digunakan berupa metode multi criteria decision analysis (MCDA). Berdasarkan hasil analisis kebijakan untuk pengembangan lapangan " $X$ " dengan memperhitungkan kriteria ekonomi, sosial, dan HSE (Kesehatan, Keselamatan dan Lingkungan) menghasilkan suatu kesimpulan bahwa alternatif kebijakan Gross Split memiliki nilai tertinggi dibandinkan dengan kebijakan Cost Recovery dan kebijakan Cost and Fee terhadap rancangan kebijakan pengelolaan minyak dan gas.

Kata kunci: cadangan, kebijakan, minyak dan gas bumi, multi criteria decision analysis

\section{KETERANGAN ARTIKEL}

Riwayat Artikel: diterima: 15 Mei 2020; direvisi: 30 Mei 2020; disetujui: 2 Juni 2020

Klasifikasi JEL: EOO

Cara Mensitasi: Nonci, R., dkk. (2020). Analisis Kebijakan untuk Pengelolaan Minyak dan Gas (Study Kasus Lapangan "X"). JIMFE (Jurnal Ilmiah Manajemen Fakultas Ekonomi), 6(1), 79-90. https://doi.org/10.34203/jimfe.v6i1.2030

Copyright@2020. JIMFE (Jurnal Ilmiah Manajemen Fakultas Ekonomi) Universitas Pakuan

\section{PENDAHULUAN}

Salah satu sumber daya alam yang tidak terbarukan adalah minyak dan gas bumi yang berperan istimewa sebagai sumber energi utama di Indonesia. Penurunan stok cadangan yang terjadi saat ini akibat adanya eksploitasi 
minyak dan gas bumi yang dilakukan secara berkesinambungan. Sumber daya alam tidak terbarukan (depletable) menggambarkan sumber daya alam yang tidak mempunyai daya pembaharuan secara biologis. Hal ini membutuhkan waktu yang sangat lama dalam proses geologi pada pembentukan sumber daya alam tersebut untuk dapat siap dipakai dan diolah. Penambangan minyak dan gas bumi merupakan contoh yang memerlukan waktu dan bahkan jutaan tahun dalam pembentukannya yang disebakan oleh ketidakmampuan untuk melakukan regenerasi (non-renewable) sumber daya tersebut. Sumber daya alam ini sering disebut juga sumber daya alam yang memiliki stok yang tetap (Fauzi, 2006).

Selama 100 tahun pada industri minyak dan gas bumi nasional sudah menjalani penurunan produksi yang signifikan. Sejauh sejarah Republik Indonesia merdeka, produksi minyak nasional yang tertinggi telah terjadi sebanyak dua periode, yaitu pada tahun 1977 dan 1995 yang masing-masing mencapai 1,68 juta bpd (barrel per day) dan 1,62 juta bpd pad produksi minyak bumi. Produksi minyak Indonesia rata-rata menurun dengan natural decline rate di sekitar $12 \%$ per tahun setelah 1995. Produksi minyak yang turun dapat ditahan dengan decline rate sekitar 3\% per tahun sejak tahun 2004 (Restra KESDM, 2015).

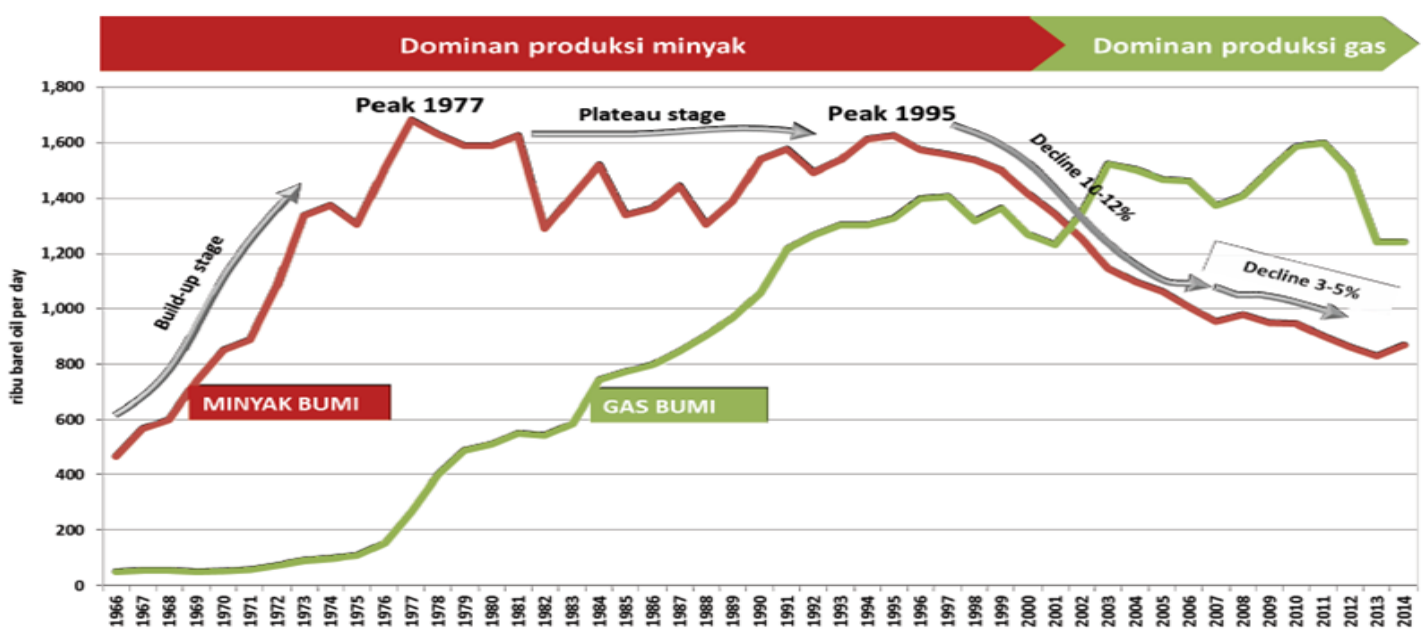

Sumber : Rencana Strategis 2015-2019 KESDM

Produksi minyak bumi berada pada 789 ribu bpd atau melemah menjadi $96 \%$ pada tahun 2014 dibandingkan tahun 2013 sebesar 824 ribu bpd. Produksi yang mengalami penurunan rata-rata sekitar $4,41 \%$ per tahun sejak tahun 2010-2014. Produksi yang turun tersebut lebih diakibatkan oleh umur beberapa lapangan minyak Indonesia yang sudah lama (tua) dan hambatan teknis dari setiap lapangan seperti unplanned shutdown, pipa yang bocor, alat-alat yang rusak, kesukaran subsurface, dan kendala alam. Selain itu, terdapat masalah non- teknis masih terjadi seperti perizinan daerah, lahan, sosial, dan keamanan.

Pada hasil gas bumi Indonesia rata-rata naik mulai tahun 1970-an, tetapi produksinya cederung tidak bergerak pada level kisaran 8.000 mmscfd (million standard cubic feet per day). Pada tahun 2014 produksi gas bumi sebesar 8.177 mmscfd. Pada tahun 2014, nilai produksi gas tersebut berbeda dengan nilai lifting gas bumi yang sekitar $6.838 \mathrm{mmscfd}$ atau 1.221 ribu boepd (barrel oil equivalent per day).

Dengan adanya produksi minyak bumi yang turun sebagai sumber daya tidak dapat 
diperbaharui (non-renewable) ini maka perlu disusun analisis kebijakan terkait pengelolaan sumber daya minyak dan gas yang dapat membagikan kemaslahatan yang sangat besar bagi seluruh lapisan masyarakat.

Salah satu sumber daya berupa minyak dan gas bumi yang memiliki nilai dan dampak produksi signifikan bagi perekonomian Indonesia, terdapat di Lapangan " $X$ " salah satu wilayah kerja di Kalimantan. Cadangan minyak dan gas bumi pada Lapangan " $X$ " mulai menghasilkan pada April 1975 menjangkau puncak produksi 26.600 bpod (barrel per day) pada tahun 1991. Mengingat pentingnya produksi minyak dan gas bumi pada Lapangan " $X$ " untuk mendukung ketahanan energi nasional.

Provinsi Kalimantan Timur merupakan daerah yang memiliki sumber daya minyak dan gas terbesar serta mempersembahkan sumbangan yang cukup besar. Di daerah ini terdapat beberapa wilayah kerja (blok) migas yang dikelola oleh masing-masing operator yang bekerja sama dengan SKK Migas Salah satu blok migas tersebut adalah lapangan " $\mathrm{X}$ " yang akan habis masa kontraknya (terminasi) pada tahun 2019.

Berdasarkan paparan tersebut, maka pertanyaan muncul dalam penelitian ini (research question) adalah pengelolaan lapangan " $X$ " dengan cara apa setelah masa terminasi. Secara umum tujuan dari penelitian ini agar dapat menyampaikan rekomendasi pengelolaan agar pemanfaatan minyak dan gas yang tersisa lebih optimal.

Ruang lingkup yang tercakup dalam penelitian ini dibatasi pada wilayah kerja migas yang berada pada Lapangan " $X$ " di selat Makassar Kalimantan Timur. Penelitian ini untuk mengkaji kebijakan pada pemanfaatan minyak dan gas yang tersisa lebih optimal dari perubahan kebijakan Kontrak Bagi Hasil (Production Sharing Contract) Cost Recovery menjadi Kontrak Bagi Hasil (Gross Split) yang di operasikan oleh PT. CPX serta kebijakan Cost and Fee sebagai alternatif pembanding kebijakan lainya.

\section{KAJIAN LITERATUR}

UU Nomor 22 Tahun 2001, minyak bumi yang dihasilkan perusahaan/kontraktor akan dibagi sebesar $85 \%: 15 \%$ dan gas bumi sebesar 70\%:30\% di antara pemerintah dengan perusahaan/kontraktor. Beberapa komponen yang mendominasi hasil bagi produksi migas adalah Gross Revenue, First Tranche Petroleum, Investment Credit dan Cost Recovery.

Menteri Energi dan Sumber Daya Mineral mengeluarkan peraturan Nomor 08 tahun 2017 yang membahas tentang kontrak bagi hasil gross split. Kontrak bagi hasil gross split adalah suatu kontrak bagi hasil berdasarkan prinsip pembagian gross produksi tanpa mekanisme pengembalian biaya operasi. Kontrak bagi hasil gross split mempergunakan metode bagi hasil awal (base split) yang dapat disesuaikan berdasarkan komponen variabel dan komponen progresif. Minyak bumi mempunyai pembagian awal (base spill) untuk sebesar $57 \%$ bagian Negara dan $43 \%$ bagian kontraktor dan gas bumi sebanyak $52 \%$ bagian negara dan $48 \%$ bagian kontraktor.

Model cost \& fee adalah model alternatif yang sudah diterapkan oleh pemerintah dan merupakan modifikasi dari bentuk kontrak bagi hasil (production sharing contract). Persyaratan primer yang wajib dilaksanakan dalam Kontrak Kerja Sama pada model ini dalam UU Migas No. 22/2001, yaitu: Sumber daya alam dimiliki oleh pemerintah; Pengoperasi berada pada manajemen Badan Pelaksana; Badan Usaha atau Bentuk Usaha Tetap menanggung modal dan risiko; Satu wilayah kerja dalam satu badan hukum; Untuk kebutuhan dalam negeri terpenuhi maka kontraktor harus menpersembahkan paling banyak $25 \%$ bagiannya dari hasil produksi Minyak Bumi (Kadir \& Suzandi, 2005). 


\section{Analisis Kebijakan Minyak dan Gas Lapangan "X"}

Khojastehmehr, dkk (2019) melakukan penelitian pada pemiihan metode yang terbaik yang akan digunakan dalam teknik pengambilan minyak bumi (enhanced oil recovery-EOR) di Iran dengan menggunakan algoritma TOPSIS. Hasil penemuan yang terbaik dalam metode tersebut adalah teknik injeksi $\mathrm{CO} 2$, uap (steam), selanjutnya injeksi nitrogen adalah urutan pilihan terbaik.

Yacine, dkk. (2019) meneliti masalah banyaknya kecelakaan kerja yang terjadi pada lapangan minyak dan gas yang sudah tua di Aljazair. Instalasi di lapangan minyak tersebut sudah berusia lebih dari tiga puluh tahun dan masih beroperasi. Untuk menangani masalah penting pada lapangan tua tersebut, otoritas Aljazair telah meluncurkan jadwal rehabilitasi dan modernisasi instalasi. Dalam kerangka program ini, banyak operasi audit dimulai untuk menguraikan diagnosis umum dari pekerjaan yang akan dilakukan sambil mengoptimalkan produksi. Dengan kata lain, risiko penuaan industri harus dikendalikan. Tujuan dari penelitian ini adalah untuk mempelajari masalah penuaan instalasi industri Aljazair melalui indikator yang diusulkan dengan teknik topsis untuk urutanpreferensi oleh kesamaan dengan metode solusi ideal yang memungkinkan identifikasi solusi kontrol penuaan lapangan minyak dan gas yang ada di fasilitas darat.

Raheditya (2016) melakukan penelitian terhadap proyek booster kompresor yang akan dipakai untuk menjaga produksi gas bumi lapangan offshore I-Parigi di PT PEP dengan metode AHP dan Topsis dengan memperhitungkan kriteria finansial dan kriteria tekinis. Total Goverment Income, Net Present Value dan Pay Out Time meliputi kriteria finansial, sedangkan delivery time project, conventionality, flexibility, process dan integrity meliputi kriteria teknis. Keputusan alternative- 8 merupakan investasi terbaik dari beberapa pilihan yang ada dalam penelitian ini.
Keputusan alternative-8 merupakan keputusan terbaik dari hasil perhitungan Topsis yang sudah dilakukan.

Tampubolon (2015) yang melakukan penelitian untuk menganalisis permasalahan yang terjadi di area pembangkit listrik tenaga panas bumi berdasarkan persepsi masyarakat dan menperkirakan biaya ekonomi dari segi konpensasi dengan metode effect on production, besaran biaya produksi diukur dengan menghitung biaya sosial yang timbul dengan metode benefit transfer dan biaya produksi listrik, serta kebijakan dianalisis dengan metode multicriteria decision analysis (MCDA). Hasil kesimpulan menunjukkan bahwa pembangkit listrik tenaga bumi memiliki nilai yang paling tinggi jika dibandinkan dengan PLTD dan PLTU dengan memperhitungkan kriteria lingkungan, sosial, dan ekonomi.

Sumber daya minyak dan gas bumi yang memiliki nilai dan dampak produksi signifikan bagi perekonomian Indonesia, terdapat di lapangan " $X$ " Wilayah Kerja di Kalimantan yang berada pada daerah operasi selatan yang dioperasikan oleh PT CPX. Cadangan minyak dan gas bumi pada lapangan " $X$ " mulai menghasilkan pada April 1975, menjangkau puncak produksi 26.600 barel per hari (BOPD) pada tahun 1991.

Mengingat pentingnya produksi lapangan " $X$ " untuk mendukung ketahanan energi secara nasional, maka peneliti menganggap penting untuk dilakukannya penelitian terhadap aternatif kebijakan migas yang terbaik untuk lapangan " $X$ ". Alternatif kebijakan migas yang akan dibandingkan dalam penelitian ini adalah alternatif kebijakan cost recovery (CR), alternatif kebijakan cost and fee (CF) dan alternatif kebijakan gross split (GS). Untuk kebijakan yang saat ini digunakan dalam pengolahan lapangan " $X$ " adalah kebijakan gross split atas penunjukan langsung dari pemerintah dalam hal ini Menteri ESDM dan di bawah pengawasan dari SKK Migas.

Berikut kerangka pemikiran dalam penelitian ini. 


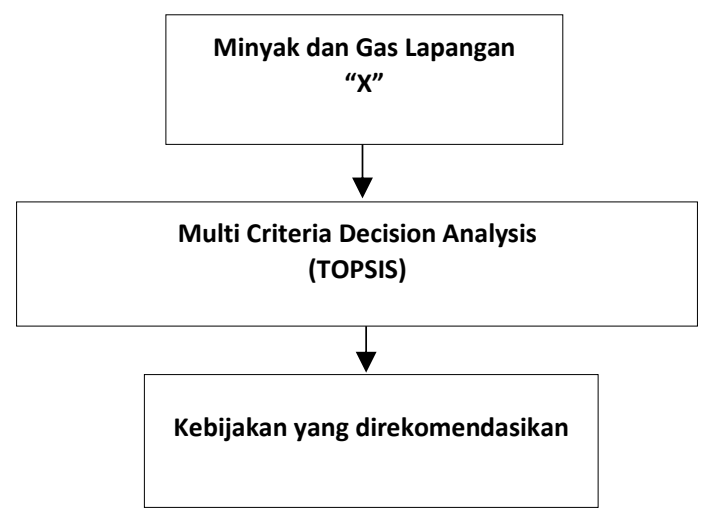

Gambar 2. Kerangka Pemikiran

\section{METODE PENELITIAN}

Penelitian ini dilaksanakan di PT CPX daerah operasi area selatan pada lapangan " $X$ " yang dilakukan secara sengaja (purposive) dengan pertimbangan bahwa lapangan tersebut sebagai pemasok utama minyak dan gas sebagai bahan baku pengelolaan refenery di Balikpapan. Sumber data sekunder yang diperoleh dari laporan instansi terkait, data pendukung dari perusahaan yang sudah tersedia berupa data dokumenter, serta berbagai penelitian sebelumnya yang berhubungan dengan penelitian ini. Untuk sumber data primer disusun langsung oleh peneliti dari para responden pada MaretAgustus 2019. Menurut Sekaran (2006), salah satu metode pengumpulan data primer adalah berdiskusi dengan narasumber untuk memperoleh informasi mengenasi isu yang diteliti. Pemilihan responden key person menggunakan non-probability sampling dengan metode purposive sampling. Kaidah tersebut dipergunakan karena sampel yang secara sengaja dipilih untuk menjadi seorang responden dengan kriteria responden tersebut memahami atau ahli dalam industri migas. Responden pada penelitian ini sebanyak empat orang yang terdiri atas pihak perusahaan pengelolah lapangan " $X$ ", pihak pemerintah, BUMN Migas, dan akademisi.

\section{Analisis Kebijakan}

Pembuatan keputusan untuk permasalahan dengan berbagai kriteria penentuan sering kali melibatkan persaingan kepentingan di antara grup, konflik tujuan, dan perbedaan tipe informasi (Bergh, 1999). Berbagai kriteria pada masalah tersebut dapat diselesaikan dengan menggunakan metode multicriteria decision analysis (MCDA) dengan pendekatan TOPSIS (Technique for Order Preference by Similarity to Ideal Solution). Prinsip sederhana dalam penentuan pilihan dengan TOPSIS adalah alternatif pilihan merupakan pilihan terdekat dengan solusi ideal positif dan yang terjauh dari solusi ideal negatif (Kahraman, 2008). Tahaptahap yang digunakan dalam penelitian ini menggunakan pendekatan TOPSIS (Wang, 2009):

Tahapan pertama dengan membangun matriks keputusan terhadap kebijakan pengelolaan minyak dan gas lapangan " $X$ ". Pada hipotesis awal akan ditemukan sejumlah m alternatif $A i(i=1,2, \ldots, m)$ yang akan diukur atas sejumlah $\mathrm{n}$ kriteria $C j(j=1,2, \ldots, n)$. Kriteria dan sub kriteria yang dipergunakan dalam analisis kebijakan ditampilkan dalam Tabel 1. 
Ramli Nonci: Analisis Kebijakan untuk ...

Tabel 1. Kriteria dan Sub Kriteria dalam Penelitian

\begin{tabular}{|c|c|c|c|}
\hline Kriteria & Sub Kriteria & Satuan & Deskripsi Kriteria \\
\hline \multirow{6}{*}{$\begin{array}{l}\text { Ekonomi } \\
\text { (EKO) }\end{array}$} & $\begin{array}{l}\text { Government of } \\
\text { Indonesia (GOI) }\end{array}$ & $\%$ & $\begin{array}{l}\text { Pembagian bagi hasil terhadap } \\
\text { pemerintah Indonesia }\end{array}$ \\
\hline & $\begin{array}{l}\text { Kontraktor Kontrak } \\
\text { Kerja Sama (K3S) }\end{array}$ & $\%$ & $\begin{array}{l}\text { Pembagian bagi hasil terhadap } \\
\text { kontraktor }\end{array}$ \\
\hline & $\begin{array}{l}\text { Komponen Progresif } \\
\text { (KP) \& Komponen } \\
\text { Variabel (KV) }\end{array}$ & $\%$ & $\begin{array}{l}\text { Komponen tambahan terhadap } \\
\text { kontraktor }\end{array}$ \\
\hline & Harga (HG) & Rp/barel & $\begin{array}{l}\text { Harga rata-rata tertimbang Minyak Bumi } \\
\text { lapangan " } X \text { " }\end{array}$ \\
\hline & Biaya (BY) & Rp/barel & $\begin{array}{l}\text { Biaya produksi untuk setiap barel minyak } \\
\text { bumi lapangan " } X \text { " }\end{array}$ \\
\hline & Cadangan (Stock) & barel & $\begin{array}{l}\text { Cadangan sumber daya Minyak bumi } \\
\text { yang dimiliki lapangan" } X \text { " }\end{array}$ \\
\hline Sosial (SOS) & Tenaga Kerja (TK) & Orang & $\begin{array}{l}\text { Jumlah tenaga kerja tetap (WNI) yang } \\
\text { terserap }\end{array}$ \\
\hline \multirow{3}{*}{$\begin{array}{l}\text { Health, } \\
\text { Safety and } \\
\text { Enviroment } \\
\text { (HSE) }\end{array}$} & Health $(\mathrm{H})$ & $\begin{array}{c}\text { Skala } \\
\text { Likert } \\
(1-5) \\
\end{array}$ & $\begin{array}{l}\text { Kebijakan K3S terhadap kesehatan pada } \\
\text { pengelolaan lapangan " } X \text { ". }\end{array}$ \\
\hline & Safety (S) & $\begin{array}{c}\text { Skala } \\
\text { Likert } \\
(1-5)\end{array}$ & $\begin{array}{l}\text { Kebijakan K3S terhadap keselamatan } \\
\text { pada pengelolaan lapangan " } \mathrm{X} \text { ". }\end{array}$ \\
\hline & Enviroment (E) & $\begin{array}{l}\text { Skala } \\
\text { Likert } \\
(1-5)\end{array}$ & $\begin{array}{l}\text { Kebijakan K3S terhadap lingkungan pada } \\
\text { pengelolaan lapangan " } X \text { ". }\end{array}$ \\
\hline
\end{tabular}

Penyusun kebijakan (decision maker) memberikan penilain individual dalam penetapan vektor nilai $W=(w 1, w 2, \ldots, w j, \ldots$ $w j)$. Nilai vektor (W) mempresentasikan relevansi relatif dari $\mathrm{n}$ kriteria $C j(j=1,2, \ldots, n)$ dalam keputusan yang ditentukan. Penampilan matriks keputusan sesuai dengan persamaan berikut:

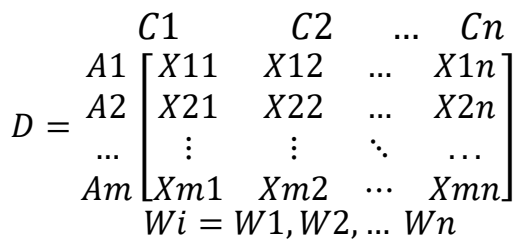

Selanjutnya menghitung matriks keputusan yang ternormalisasi dari kriteria yang sudah dilakukan penyusunan. Nilai estimasi dari setiap kriteria dapat didapat dari kalkulasi matriks keputusan yang telah dinormaliasasi. Rumus untuk kalkulasi matriks keputusan ternormalisasi adalah sebagai berikut;

$$
n_{i j}=\frac{x i j}{\sqrt{\sum_{i}^{m} x_{i j}^{2}}} ; i=1, \ldots,=1, \ldots n ;
$$

Tahapan selanjutnya dengan mempertimbangkan matriks keputusan normal ternilai. Pada matriks keputusan normal ternilai (Vij) dihitung dengan memakai persamaan di bawah ini;

$$
V_{i j}=W_{j} n_{i j}, i=1, \ldots, m ; j=1, \ldots n
$$

dimana $\left(V_{i j}\right)$ adalah nilai dari kriteria ke-j dan besaran dari nilai keseluruhan adalah 1

$$
\left(\sum_{j=1}^{n} W j=1\right)
$$

Penentuan solusi ideal positif $(A+)$ dan solusi ideal negatif $(A-)$ dilakukan pada 
tahapan berikutnya. Perhitungan yang dipergunakan untuk mendapatkan solusi ideal positif $(A+)$ dan solusi ideal negatif $(A-)$ menpergunakan rumus seperti di bawah;

$$
\begin{aligned}
A^{+}= & \left\{v_{1}{ }^{+}, \ldots, v_{n}{ }^{+}\right\}\left\{\left(\max _{j} V_{i j}, i\right.\right. \\
& \left.\in I) \mid\left(\min _{j} V_{i j}, i \in I\right)\right\} \quad(4) \\
A^{-}= & \left\{v_{1}{ }^{-}, \ldots, v_{n}-\right\}\left\{\left(\min _{j} V_{i j}, i\right.\right. \\
& \left.\in J) \mid\left(\max _{j} V_{i j}, i \in I\right)\right\} \quad(5)
\end{aligned}
$$

dimana $v i+$ sebagai tanda nilai maksimum dari $V i j$ dan $v i$ - sebagai tanda nilai minimum dari $V i j$. I adalah berkaitan dengan kriteria manfaat dan $J$ diasumsikan dengan kriteria cost.

Penentuan jarak solusi ideal positif $(\mathrm{di+})$ dan solusi ideal negatif (di-). Penggunakan persamaan dibawah untuk menghitung jarak solusi ideal positif sebagai berikut:

$$
d_{i}^{+}=\left\{\sum_{j=1}^{n}\left(v_{i j}-v_{j}^{+}\right)^{2}\right\}^{1 / 2}, i=1, \ldots m
$$

Pemisahan dari solusi ideal negatif dihitung dengan rumus dibawah;

$$
d_{i}^{-}=\left\{\sum_{j=1}^{n}\left(v_{i j}-v_{j}^{-}\right)^{2}\right\}^{1 / 2}, i=1, \ldots m
$$

Tahapan pada penerapan koefisien terdekat (closeness coeficient) ( $\mathrm{Ci}$ ). Penetapan rangking setiap alternaltif dengan menetapkan koefisien terdekat. $\mathrm{Ci}$ dihitung sesuai dalam persamaan di bawah;

$$
\mathrm{C}_{1}=\frac{\mathrm{d}_{\mathrm{i}}^{-}}{\left(\mathrm{d}_{\mathrm{i}}^{+}+\mathrm{d}_{\mathrm{i}}^{-}\right)} ; \mathrm{i}=1, \ldots, \mathrm{m}
$$

Setiap kebijakan yang diuji ditentukan urutannya yang merupakan tahapan terakhir pada metoda Topsis. Nilai koefisien terdekat (Ci) yang nilainya paling tinggi merupakan pilihan yang terbaik pada urutan solusi terbaik pada alternative kebijakan pengelolaan migas. Untuk menguji kebijakan yang terpilih selanjutnya dilakukan uji sensitivitas agar dapat melihat adanyapengaruh pada ketidakpastian terhadap model pengambilan keputusan yang telah dibuat.

\section{HASIL DAN PEMBAHASAN}

Seperti diketahui bahwa kegiatan ekplorasi dan eksploitasi minyak dan gas bumi di Indonesia sudah berlangsung lama. Sebagian lapangan telah berumur sangat tua dan lapangan- lapangan tua tersebut sering kali diserahterimakan dari stakeholder kepada perusahaan minyak dan gas bumi nasional atau KKKS Nasional. Dalam penelitian yang dilakukan oleh Lita Liana (2014), menyebutkan bahwa lapangan di area Indonesia sebagian besar berupa marginal field. Artinya, nilai cadangan minyak dan gas bumi yang ada di resevoir sering kali tidak sesuai dengan hasil perkiraan cadangan yang sudah dilakukan proses studi dan kajian subsurface.

Cadangan lapangan " $X$ " yang memiliki sumber daya minyak dan gas yang terbatas mengalami proses terminasi akan mendatangkan masalah dalam pengelolaannya jika kebijakan yang diterapkan tidak sesuai. Untuk itu perlu mempertimbangkan beberapa aspek, di antaranya ekonomi, sosial, dan lingkungan (HSE) dalam pemilihan aternatif kebijakan migas. Hal ini untuk mengembangkan sumber daya minyak dan gas yang tersisa pada lapangan " $X$ ", sehingga alih kelola dapat berlangsung dengan baik dan berkesinambungan untuk pemenuhan kebutuhan energi di masa mendatang.

Untuk itu perlu untuk melihat peringkat aternatif-alternatif kebijakan yang digunakan pada lapangan " $X$ ". Alternatif-alternatif kebijakan tersebut perlu untuk diuji dengan suatu metode kebijakan yang diambil dapat terukur dan terencana. Salah satu metode yang digunakan adalah metode Topsis untuk memberikan peringkat alternatif-alternatif kebijakan pada matriks keputusan.

Hasil analisa kebijakan pada penelitian ini menggunakan metode multi-criteria decision analysis untuk pengembangan Lapangan " $X$ " yang telah mempertimbangkan berbagai macam kriteria dengan pilihan-pilihan model alternatif kebijakan pengelolaan minyak dan gas bumi di lapangan " $X$ ". Pada tabel 2 dapat dilihat kriteria dan sub kriteria yang digunakan dalam penelitian ini. Kriteria dan alternatif yang digunakan sebagai dasar pembuatan kebijakan, ditampilkan dalam sebuah hirarki yang disajikan dalam gambar 3 . 


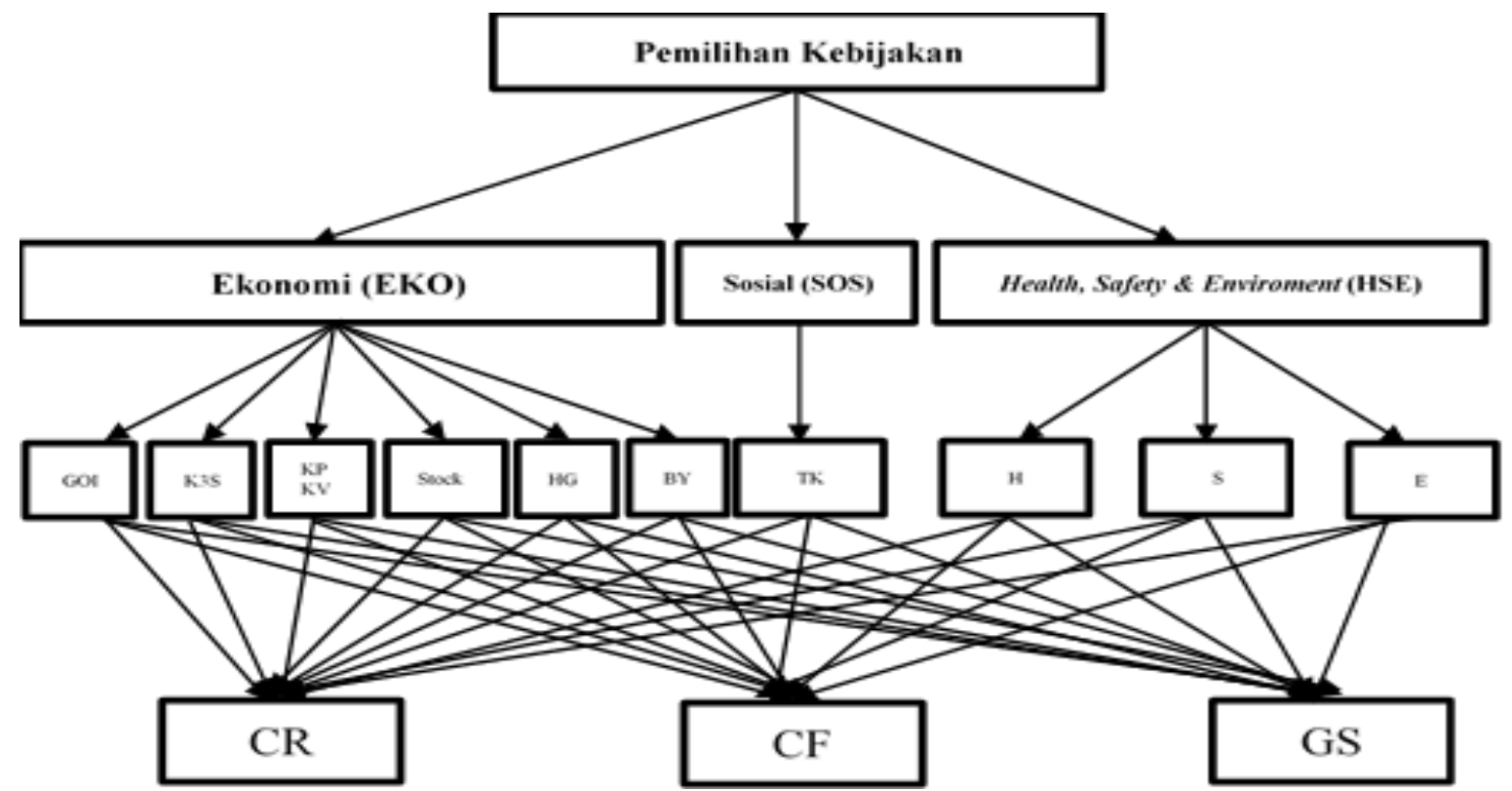

Gambar 3. Hirarki pembuatan alternatif kebijakan

Proses pemilihan keputusan untuk menentukan alternatif kebijakan pengelolaan minyak dan gas bumi yang terbaik dengan memperhitungkan kriteria Ekonomi, Sosial, dan HSE dianalisis berdasarkan proses tahapan sebagai berikut;

Matriks keputusan yang telah disusun dengan sepuluh sub kriteria $(C j(j=1,2, \ldots, 10))$ pengelolaan minyak dan gas bumi lapangan " $\mathrm{X}$ "

yang merupakan komponen dari tiga kriteria utama serta terdapat 3 alternaltif $(A i(i=1,2,3))$ alternatif pengelolaan sumber daya minyak dan gas yang akan ditentukan nilainya. Hasil penilaian dari para pemangku kebijakan (stakeholder) diperlihatkan pada tabel 2.

Tabel 2. Hasil Penilaian Pemangku Kebijakan

\begin{tabular}{cccccc}
\hline Sub Kriteria & \multicolumn{5}{c}{ Nilai } \\
\cline { 2 - 6 } & PT CPX & KESDM & BUMN & Akademis & $\begin{array}{c}\text { Nilai } \\
\text { Rata-rata }\end{array}$ \\
\hline GOI & 5 & 4 & 5 & 5 & 0,120 \\
K3S & 4 & 2 & 4 & 4 & 0,093 \\
Stock & 5 & 4 & 5 & 5 & 0,127 \\
KP\&KV & 4 & 3 & 3 & 3 & 0,087 \\
HG & 4 & 5 & 4 & 4 & 0,113 \\
BY & 3 & 4 & 3 & 3 & 0,087 \\
TK & 3 & 5 & 3 & 3 & 0,093 \\
H & 3 & 5 & 3 & 3 & 0,093 \\
S & 3 & 5 & 3 & 3 & 0,093 \\
E & 3 & 5 & 3 & 3 & 0,093 \\
\hline
\end{tabular}


Pemangku kebijakan terdiri dari sektor pemerintah yang diwakili KESDM, BUMN (Pertamina), sektor akademisi dan peneliti, dan sektor perusahaan diwakili oleh PT. CPX dimana perusahaan yang mengelola lapangan " $X$ ". Penilaian nilai terhadap masing-masing sub kriteria berasal dari para pemangku kebijakan. Hasil responde pada penentuan nilai pada 10 kriteria yang ditetapkan mendapatkan nilai yang bervariasi dengan nilai stock menempati nilai yang paling tinggi dengan pertimbangan bahwa kriteria tersebut merupakan kriteria utama pada keberlanjutan dari bisnis minyak dan gas bumi ditanah air. Selanjutnya nilai harga GOI yang merupakan nilai kedua yang memiliki nilai tertinggi dengan pertimbangan para kosioner bahwa pembagian terhadap bagian dari pemerintah harus mempunyai bagian yang lebih besar terhadap pembagian hasil akhir minyak dan gas bumi karena hal ini akan digunakan sebesarbesarnya bagi masyarakat sekitar lapangan minyak dan gas serta masyarkat secara umum. Nilai harga dari minyak dan gas bumi ikut mempengaruhi pada nilai tersebut dimana beberapa faktor eksternal didunia akan sangat mempengaruhi harga dari minyak dan gas bumi sebagai pertimbangan dari tanggapan kuisioner. Tampilan matriks keputusan dari pemilihan alternatif kebijakan pengelolaan minyak dan gas bumi yang terbaik dilihat pada tabel 3.

Tabel 3. Matriks Keputusan

\begin{tabular}{|c|c|c|c|c|c|c|c|c|c|c|}
\hline \multirow{4}{*}{ 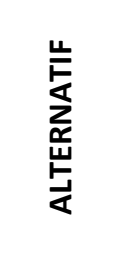 } & \multicolumn{10}{|c|}{ KRITERIA } \\
\hline & \multicolumn{6}{|c|}{ EKONOMI } & \multirow{3}{*}{$\begin{array}{c}\text { SOSIAL } \\
\text { TK } \\
\left(C_{7}\right)\end{array}$} & \multicolumn{3}{|c|}{$\begin{array}{c}\text { Health, Safety \& } \\
\text { Enviroment (HSE) }\end{array}$} \\
\hline & GOI & K3S & Stock & KP\&KV & HG & BY & & H & $\mathbf{S}$ & $E$ \\
\hline & $\left(C_{1}\right)$ & $\left(C_{2}\right)$ & $\left(C_{3}\right)$ & $\left(C_{4}\right)$ & $\left(C_{5}\right)$ & $\left(C_{6}\right)$ & & $\left(C_{8}\right)$ & $\left(C_{9}\right)$ & $\left(C_{10}\right)$ \\
\hline $\mathrm{CR}\left(A_{1}\right)$ & $85^{a}$ & $15^{a}$ & $\begin{array}{c}325748084 \\
c\end{array}$ & $0^{d}$ & $\begin{array}{c}716660 \\
e\end{array}$ & $\underset{f}{161000}$ & $1500^{g}$ & $5^{h}$ & $5^{h}$ & $4^{h}$ \\
\hline $\operatorname{CF}\left(A_{2}\right)$ & $63^{b}$ & $37^{b}$ & $\begin{array}{c}322988294 \\
c\end{array}$ & $0^{d}$ & $\begin{array}{c}944580 \\
e\end{array}$ & $\underset{f}{179200}$ & $1500^{\mathrm{g}}$ & $5^{h}$ & $4^{h}$ & $4^{h}$ \\
\hline $\mathrm{GS}\left(A_{3}\right)$ & $57^{a}$ & $43^{a}$ & $\begin{array}{c}322988294 \\
c\end{array}$ & $29,64^{d}$ & $\begin{array}{c}944580 \\
\mathrm{e}\end{array}$ & $\underset{f}{179200}$ & $552^{g}$ & $5^{\mathrm{h}}$ & $5^{h}$ & $5^{h}$ \\
\hline $\begin{array}{l}\text { Nilai } \\
(W)\end{array}$ & 0,120 & 0,093 & 0,127 & 0,087 & 0,133 & 0,087 & 0,093 & 0,093 & 0,093 & 0,093 \\
\hline
\end{tabular}

Sumber:

$\mathrm{a}=\mathrm{KESDM}$

$b=\mid$ ATMI 2005-39 c, d,e,f \& g = PT. CPX 2018

$\mathrm{h}=$ Data Primer 2019

Tabel 4. Matriks Keputusan Ternormalisasi

\begin{tabular}{lcccccccccc}
\hline & MAX & MAX & MAX & MAX & MAX & MAX & MAX & MAX & MAX & MAX \\
\hline & GOI & KKKS & STOCK & $\begin{array}{c}\text { KP \& } \\
\text { KV }\end{array}$ & HG & BY & TKN & H & S & E \\
\hline 1.CR & 0,70728 & 0,25564 & 0,58063 & 0,00000 & 0,47275 & 1,00000 & 0,00000 & 0,57735 & 0,61546 & 0,52981 \\
\hline 2.CF & 0,52422 & 0,63057 & 0,57571 & 0,00000 & 0,62310 & 0,00000 & 0,00000 & 0,57735 & 0,49237 & 0,52981 \\
\hline 3.GS & 0,47429 & 0,73282 & 0,57571 & 1,00000 & 0,62310 & 0,00000 & 1,00000 & 0,57735 & 0,61546 & 0,66227 \\
\hline Weights & $\mathbf{0 , 1 2 0 0 0}$ & $\mathbf{0 , 0 9 3 3 3}$ & $\mathbf{0 , 1 2 6 6 7}$ & $\mathbf{0 , 0 8 6 6 7}$ & $\mathbf{0 , 1 1 3 3 3}$ & $\mathbf{0 , 0 8 6 6 7}$ & $\mathbf{0 , 0 9 3 3 3}$ & $\mathbf{0 , 0 9 3 3 3}$ & $\mathbf{0 , 0 9 3 3 3}$ & $\mathbf{0 , 0 9 3 3 3}$ \\
\hline
\end{tabular}

Sumber: Data primer yang diolah, 2019 
Hasil yang didapatkan dalam pengelolaan dengan menggunakan perangkat lunak (Software Sanna) tersebut ditampilkan dalam tabel 4. Perubahan terlihat pada angka yang terdapat di kolom setiap kriteria yang dipakai. Angka tersebut merupakan hasil perhitungan dari persamaan mempertimbangkan matriks keputusan ternormalisasi.
Menghitung matriks keputusan normal ternilai dari kriteria yang disusun. Data hasil perhitungan untuk membuat matriks normal ternilai diperlihatkan pada tabel 5. Hasil wawancara dengan para key person mengalami perubahan menjadi nilai yang ideal berdasarkan hasil perhitungan. Nilai pada kolom memperlihatkan nilai yang sudah ternormalisasi pada setiap kriteria-kriteria yang dilakukan pengujian.

Tabel 5. Matriks Keputusan Normal Ternilai

\begin{tabular}{llccccccccc}
\hline & MAX & MAX & MAX & MAX & MAX & MAX & MAX & MAX & MAX & MAX \\
\hline & GOI & KKKS & STOCK & KP \& KV & HG & BY & TKN & H & S & E \\
\hline 1.CR & 0,08487 & 0,02386 & 0,07355 & 0,00000 & 0,05358 & 0,08667 & 0,00000 & 0,05389 & 0,05744 & 0,04945 \\
\hline 2.CF & 0,06291 & 0,05885 & 0,07292 & 0,00000 & 0,07062 & 0,00000 & 0,00000 & 0,05389 & 0,04595 & 0,04945 \\
\hline 3.GS & 0,05692 & 0,06840 & 0,07292 & 0,08667 & 0,07062 & 0,00000 & 0,09333 & 0,05389 & 0,05744 & 0,06181 \\
\hline Weights & $\mathbf{0 , 1 2 0 0 0}$ & $\mathbf{0 , 0 9 3 3 3}$ & $\mathbf{0 , 1 2 6 6 7}$ & $\mathbf{0 , 0 8 6 6 7}$ & $\mathbf{0 , 1 1 3 3 3}$ & $\mathbf{0 , 0 8 6 6 7}$ & $\mathbf{0 , 0 9 3 3 3}$ & $\mathbf{0 , 0 9 3 3 3}$ & $\mathbf{0 , 0 9 3 3 3}$ & $\mathbf{0 , 0 9 3 3 3}$ \\
\hline Ideal & $\mathbf{0 , 0 8 4 8 7}$ & $\mathbf{0 , 0 6 8 4 0}$ & $\mathbf{0 , 0 7 3 5 5}$ & $\mathbf{0 , 0 8 6 6 7}$ & $\mathbf{0 , 0 7 0 6 2}$ & $\mathbf{0 , 0 8 6 6 7}$ & $\mathbf{0 , 0 9 3 3 3}$ & $\mathbf{0 , 0 5 3 8 9}$ & $\mathbf{0 , 0 5 7 4 4}$ & $\mathbf{0 , 0 6 1 8 1}$ \\
\hline Basal & $\mathbf{0 , 0 5 6 9 2}$ & $\mathbf{0 , 0 2 3 8 6}$ & $\mathbf{0 , 0 7 2 9 2}$ & $\mathbf{0 , 0 0 0 0 0}$ & $\mathbf{0 , 0 5 3 5 8}$ & $\mathbf{0 , 0 0 0 0 0}$ & $\mathbf{0 , 0 0 0 0 0}$ & $\mathbf{0 , 0 5 3 8 9}$ & $\mathbf{0 , 0 4 5 9 5}$ & $\mathbf{0 , 0 4 9 4 5}$ \\
\hline
\end{tabular}

Sumber: Data primer yang diolah, 2019

Pada penentuan solusi dan jarak solusi ideal positif, serta solusi ideal negatif $(A+),(A-),(d i+),(d i-)$ dengan menggunakan program Sanna ditampilkan dalam tabel 6 . Pada tabel menunjukkan nilai solusi positif untuk GS 0,091 dan solusi ideal negatif sebesar 0,137 . Angka-angka dalam alternatif GS mendekati solusi ideal jika dibandingkan dengan angka-angka pada CR dan angka-angka CF serta nilai GS mempunyai jarak terjauh dari solusi ideal negatif jika dilakukan perbandingan alternatif kebijakan pengelolaan lapangan " $\mathrm{X}$ " yang lainnya.

Tabel 6. Jarak Solusi Ideal Positif dan Ideal Negatif

\begin{tabular}{|c|c|c|c|c|c|c|c|c|c|c|c|c|}
\hline & MAX & MAX & MAX & MAX & MAX & MAX & MAX & MAX & MAX & MAX & & \\
\hline & GOI & KKKS & STOCK & $\begin{array}{c}\text { KP \& } \\
\text { KV }\end{array}$ & HG & BY & TKN & $\mathrm{H}$ & $S$ & E & dit & di- \\
\hline 1.CR & 0,08487 & 0,02386 & 0,07355 & 0,00000 & 0,05358 & 0,08667 & 0,00000 & 0,05389 & 0,05744 & 0,04945 & 0,13656 & 0,09179 \\
\hline 2.CF & 0,06291 & 0,05885 & 0,07292 & 0,00000 & 0,07062 & 0,00000 & 0,00000 & 0,05389 & 0,04595 & 0,04945 & 0,15682 & 0,03938 \\
\hline $3 . G S$ & 0,05692 & 0,06840 & 0,07292 & 0,08667 & 0,07062 & 0,00000 & 0,09333 & 0,05389 & 0,05744 & 0,06181 & 0,09107 & 0,13704 \\
\hline Weights & 0,12000 & 0,09333 & 0,12667 & 0,08667 & 0,11333 & 0,08667 & 0,09333 & 0,09333 & 0,09333 & 0,09333 & & \\
\hline Ideal & 0,08487 & 0,06840 & 0,07355 & 0,08667 & 0,07062 & 0,08667 & 0,09333 & 0,05389 & 0,05744 & 0,06181 & & \\
\hline Basal & 0,05692 & 0,02386 & 0,07292 & 0,00000 & 0,05358 & 0,00000 & 0,00000 & 0,05389 & 0,04595 & 0,04945 & & \\
\hline
\end{tabular}

Sumber: Data primer yang diolah, 2019

Penentuan urutan koefisien terdekat untuk masing-masing alternatif disajikan dalam tabel 7. Koefisien ini merupakan nilai akhir yang dihitung untuk dapat menentukan urutan terbaik dari alternatif yang tersedia. Alternatif kebijakan gross split (GS) adalah alternatif kebijakan yang terpilih menjadi kebijakan yang terbaik, diikuti dengan cost and fee (CF) dan cost recovery (CR). 
Tabel 7. Koefisien Terdekat Alternatif Kebijakan pada Lapangan " $X$ " (Final Ranking)

\begin{tabular}{ccc}
\hline Ranking & Alternative & R.U.V \\
\hline 1 & $3 . G S$ & 0,6008 \\
2 & 1.CR & 0,4020 \\
3 & $2 . C F$ & 0,2007 \\
\hline
\end{tabular}

Sumber: Data primer yang diolah, 2019

Komposisi alternaltif kebijakan pengelolaan lapangan " $\mathrm{X}$ " jika pemerintah ingin menerapkan model pengembangan bussiness as usual dengan nilai key person dan setara (equal rates), maka pilihan pengembangan lapangan minyak dan gas bumi adalah GS, CR dan CF. Perubahan harga dan biaya pada masing-masing alternatif serta nilai kriteria sesuai dengan hasil key person (HG-BY+KP) dan equal rate (HG-BY+ER) menghasilkan pilihan GS menjadi pilihan pertama.

Tabel 8. Hasil Perhitungan Koefisien Terdekat dan Uji Sensitivitas Kebijakan Pengelolaan Minyak dan Gas Lapangan " $X$ "

\begin{tabular}{lcccc}
\hline Alternatif & \multicolumn{4}{c}{ Dengan Uji Sensitivitas } \\
\cline { 2 - 5 } & BAU + KP & BAU +ER & HG-BY +KP & HG-BY+ER \\
\hline GS & 0,6008 & 0,5954 & 0,5987 & 0,5940 \\
CR & 0,4020 & 0,4071 & 0,4041 & 0,4085 \\
CF & 0,2007 & 0,1884 & 0,1846 & 0,1774 \\
\hline
\end{tabular}

Keterangan:

BAU+KP : harga dan biaya sesuai bussiness as usual dan nilai sesuai keyperson

BAU+ER : harga dan biaya sesuai bussiness as usual dan nilai sesuai equal rates

$\mathrm{HG}-\mathrm{BY}+\quad$ : harga sesuai dengan K.P perubahan harga ICP, biaya sesuai biaya lapangan " $\mathrm{X}$ " nilai ekonomi sesuai keyperson

$\mathrm{HG}-\mathrm{BY}+\quad$ : harga sesuai dengan E.R perubahan harga ICP, biaya sesuai biaya lapangan " $\mathrm{X}$ " nilai ekonomi sesuai equal rates

\section{PENUTUP}

Berdasarkan penelitian yang berdasarkan atas permasalahan yang dirumuskan dalam hipotesis dengan menggunakan metode Topsis maka dapat diambil kesimpulan bahwa urutan alternatif kebijakan pengelolaan agar pemanfaatan sumber daya minyak dan gas yang tersisa lebih optimal dengan pertimbangan kriteria ekonomi, sosial dan HSE (Healt, Safety and Enviroment) pada lapangan " $X$ " adalah Kebijakan Gross Splitt menjadikan pilihan pertama sebagai alternatif pengelolaan lapangan " $X$ " jika dibandingkan dengan alternative kebijakan yang lainnya. Hal ini mengandung implikasi bahwa dalam pengelolaan lapangan " $X$ " sudah sesuai dengan kebijakan pemerintah dalam penerapan kebijakan Gross Split pada pengelolaan minyak dan gas pada lapangan " $\mathrm{X}$ ".

Perlu adanya penelitian lanjutan yang dapat mempertimbangkan kriteria yang lain seperti unsur eksternalitas yang dihasilkan oleh lapangan " $X$ " sehingga dapat menyajikan hasil penelitian yang lebih berkualitas. 
Ramli Nonci: Analisis Kebijakan untuk ...

\section{REFERENSI}

Fauzi, A. (2006). Ekonomi Sumber daya Alam dan Lingkungan Teori dan Aplikasi. Jakarta: PT. Gramedia Pustaka Utama.

Kadir, A dan Suzandi, E. (2005). Model Alternatif Kontrak Kerja Sama Migas. Simposium Nasional Ikatan Ahli Teknik Perminyakan Indonesia (IATMI).

Kahraman C. (2008). Fuzzy Multi-Criteria Decision-Making: Theory and Applications with Recent Developments. New York: Springer.

Khojastehmehr, M., dkk. (2019). Screening of enhanced oil recovery techniques for Iranian oil reservoirs using TOPSIS algorithm. Energy Reports, 5, (2019) 529-544.

Liana, L. (2014). Using Analytical Hierarchy Process to Determine Approriate Minimum Attractive Rate of Return for Oil and Gas Project in Indonesia. PM World Jurnal, 3(2), 1-14.

Peraturan Menteri Energi dan Sumber Daya Mineral. (2017). Nomor 08 tentang Kontrak Bagi Hasil Gross Split. Jakarta

Peraturan Menteri Energi dan Sumber Daya Mineral. (2017). Nomor 52 tentang Perubahan atas Peraturan Menteri Energi dan Sumber Daya Mineral Nomor 082017 tentang Kontrak Bagi Hasil Gross Split. Jakarta

Peraturan Pemerintah. (2014). Nomor 27 tentang Pengelolaan Barang Milik Negara/Daerah. Jakarta.

Raheditya, R. (2016). Analisa Keputusan Proyek Investasi Pemasangan Booster
Kompresor Sebagai Upaya

Mempertahankan Produksi Gas Bumi Lapangan Offshore l-Parigi di PT. PEP dengan Metode AHP dan Topsis. Tesis. ITS. Surabaya.

Renstra Kesdm. (2015). Rencana Strategis Kementrian Energi dan Sumber Daya Mineral. Kementrian Energi dan Sumber Daya Mineral. Jakarta: Kementrian Energi dan Sumber Daya Mineral.

Sekaran, U. (2006). Metodologi Penelitian untuk Bisnis. Buku Kedua Edisi Empat. Jakarta: Salemba Empat.

Society of Petroleum Engineers dan World Petroleum Council. (2007). Petroleum Resources Management System. World Petroleum Council.

Tampubolon, Bahroin I. (2015). Analisis Kebijakan Pemanfaatan Energi Panas Bumi Sebagai Alternatif Pembangkit Listrik. Bogor: Sekolah Pascasarjana Institut Pertanian Bogor.

Undang-Undang Republik Indonesia. (2009). Nomor 32 tentang Perlindungan dan Pengelolaan Lingkungan Hidup

Undang-Undang Republik Indonesia. (2001). Nomor 22 tentang Minyak dan Gas Bumi.

Wang TC, Lee HD. (2009). Developing a Fuzzy TOPSIS Approach Based on Subjective Weights and Objective Weights. Expert System with Applications. 36, 89808985. 